\title{
THE IPPAR Model sebagai Komponen Etnografi PR pada Kajian Public Relations Berbasis Budaya
}

\author{
Dasrun Hidayat \\ Fakultas Ilmu Komunikasi Universitas BSIJl. Sekolah International 6 Antapani Bandung \\ Tlp. 022-7100 124, Hp. 08132211 4521, \\ Email: dasrun.duh@bsi.ac.id \\ Engkus Kuswarno, Feliza Zubair dan Hanny Hafiar \\ Fakultas Ilmu Komunikasi, Universitas Padjadjaran Jl. Raya Sumedang Km. 21 Jatinangor \\ Tlp. 022-842 88888 \\ Email: kuswarno@unpad.ac.id \\ Email: feliza.zubair@unpad.ac.id \\ Email: hanny.hafiar@unpad.ac.id
}

\begin{abstract}
This article introduces, also offers a research findings on communication behavioral components of culture-based PR. The component consists of aspects of Insight - Strategic Programs - Implementation Program - Action and Reputation (IPPAR Model). The communication behavior component of $P R$ is a transformation of the field findings or the originality of data on Jakhu Suku's behavior patterns on giving title ceremony. The behavior pattern covers the Pekhsiapan as preparation, khencana as planning, lestakhi as execution, penghengok as support, and penghanggum as trust. The study concluded that there was a link between the findings of behavioral patterns with the conception of Jakhu Suku Public Relations and culture so that the components The IPPAR model can be classified as a component of ethnography PR. The methodology focuses on culture-based PR communication behavior. Presented on the concept, construct, basic principles, as well as the workings of the research. PR Ethnographic methodology can be applied in the context of profit and nonprofit PR organizations. So, culture-based PR activities can be applied in context of corporate PR, Government PR, and Non Government PR.
\end{abstract}

Keywords: Communication Behavior, Ethnography PR, Local Wisdom

\begin{abstract}
Abstrak
Artikel ini mengenalkan sekaligus menawarkan hasil temuan penelitian tentang komponen perilaku komunikasi PR berbasis budaya. Komponen terdiri dari aspek Insight-Program StrategicProgram Implementation-Action and Reputation atau disingkat menjadi The IPPAR Model. Komponen perilaku komunikasi PR merupakan transformasi hasil temuan lapangan atau originalitas data tentang pola perilaku Jakhu Suku pada ritual pemberian gelar. Pola perilaku meliputi tahapan pekhsiapan (persiapan), khencana (perencanaan), lestakhi (pelaksanaan), penghengok (dukungan) dan penghanggum (kepercayaan). Hasil penelitian menyimpulkan bahwa ada keterkaitan antara temuan pola perilaku Jakhu Suku dengan konsepsi Public Relations dan budaya sehingga komponen The IPPAR Model dapat dikategorikan sebagai komponen Etnografi PR. Metodologi yang fokus pada perilaku komunikasi PR berbasis budaya. Dipaparkan tentang konsep, konstruk, prinsip dasar, serta
\end{abstract}


cara kerja penelitian. Metodologi Etnografi PR dapat diterapkan pada konteks lembaga PR profit dan nonprofit. Kajian PR berbasis budaya pada konteks PR perusahaan, PR Pemerintahan, dan PR Non Pemerintahan.

Kata Kunci: Etnografi PR, Perilaku Komunikasi, The IPPAR Model

\section{Pendahuluan}

Public Relations adalah istilah lain dari Hubungan Masyarakat atau Humas, akan tetapi lebih populer dengan istilah Public Relations atau PR. Ardianto menjelaskan bahwa Humas adalah padanan kata dari PR (Ardianto, 2013:2). Hal serupa berlaku dalam penyebutan istilah Etnografi Hubungan Masyarakat, Etnografi Public Relations atau Etnografi PR atau Ethnography PR. Pada hasil penelitian ini diperkenalkan dengan istilah Etnografi PR sebagai tawaran metodologi yang berfokus pada perilaku komunikasi PR bebasis budaya. Etnografi PR merupakan hasil pemikiran secara konseptual dan teoritis yang mengacu pada temuan penelitian tentang perilaku komunikasi Jakhu Suku sebagai PR Budaya. Etnografi PR sebuah transformasi dari Etnografi Komunikasi. Terdapat banyak keterkaitan antara keduanya karena komunikasi merupakan tulang punggung aktivitas PR. Komunikasi sebagai objek material sehingga tanpa adanya komunikasi aktivitas PR tidak dapat dilakukan. Keterkaitan tersebut mendorong keinginan peneliti untuk mengkaji metodologi khusus yang digunakan dalam penelitian PR berbasis budaya.

Milton dan Sturtevent dalam (Kuswarno, 2008:10) menjelaskan bahwa ethnoscience memunculkan ethno-ethno lainnya dan Etnografi PR sebagai transformasi dari Etnografi. Etnografi PR mengacu pada kajian Etnografi Komunikasi. Hymes dalam Kuswarno menjelaskan bahwa kerangka acuan dalam memposisikan bahasa dalam suatu kebudayaan harus berfokus pada komunikasi (Kuswarno, 2008:11). Hal senada dipertegas oleh Sriramesh bahwa adanya keterkaitan budaya, komunikasi dan PR. Menurut Sriramesh fokus kajian ilmu Public Relations adalah perilaku komunikasi untuk membangun hubungan (Sriramesh, 2004:03). Kajian PR yang terus berkembang di era globalisasi menempatkan budaya di garda terdepan. Kehadiran budaya membuka peluang yang besar untuk penelitian ilmu Public Relations (Sriramesh, 2004:03). Adanya keterlibatan budaya, akan tetapi keberadaan budaya saat ini seakan menjadi mata rantai yang hilang. Untuk itu diperlukan tinjauan khusus tentang keberadaan budaya pada kajian Public Relations.

Pentingnya memahami budaya dalam konteks perilaku komunikasi Public Relations mendorong lahirnya istilah PR berbasis budaya atau PR Budaya. Perilaku komunikasi PR yang senantiasa bersandar pada budaya organisasi maupun institusi. Budaya berada di garda terdepan sehingga membuka peluang untuk mengemangkan konsep dan metodologi khusus pada kajian PR berbasis budaya. Metodologi yang dimaksud adalah Etnografi PR. Metodologi yang diharapkan dapat menjawab tujuan penelitian PR berbasis budaya.

\section{Metode Penelitian}

Penelitian ini menggunakan metode Etnografi Komunikasi. Metode yang mengkaji peranan bahasa dalam perilaku komunikatif suatu masyarakat, yaitu cara-cara bagaimana bahasa dipergunakan dalam masyarakat yang berbeda-beda kebudayaan. Seville Troike menjelaskan bahwa ruang lingkup etnografi komunikasi adalah kompetensi komunikasi. (Kuswarno, 2008:11). Etnografi Komunikasi berfokus pada perilaku komunikasi sebagai objek kajian. Tahapan Etnografi Komunikasi dimulai dari upaya identifkasi peristiwa komunikasi, melakukan inventarisasi peristiwa komunikasi yang berhubungan dengan komponen komunikasi sehingga membangun pola komunikasi. 
Penelitian ini menggunakan etnografi komunikasi karena fokus penelitian pada perilaku komunikasi Jakhu Suku sebagai pengelola tradisi pemberian gelar. Penelitian dilakukan di desa Banjar Negeri Kecamatan Gunung Alip Kabupaten Tanggamus Lampung. Fokus penelitian pada prosesi ritual pemberian gelar atau Juluk Adok. Prosesi ritual syarat akan perilaku komunikasi Jakhu Suku yang terjadi secara khas dan berulang sehingga membangun pola perilaku komunikasi Jakhu Suku. Teknik informan menggunakan purposive dengan mengambil informan perangkat adat pada masyarakat adat Saibatin Lampung. Kriteria informan adalah adanya keterlibatan secara langsung sebagai pengelola adat, penggiat budaya, sosiolog Lampung, dan pakar PR. Informan diambil sebanyak 15 orang. Teknik pengumpulan data melalui observasi berperan serta dan wawancara mendalam.

\section{Hasil Penelitian dan Pembahasan Perilaku Komunikasi Jakhu Suku}

Jakhu Suku melaksanakan prosesi ritual pemberian gelar selalu menyesuaikan dengan tahapan pemberian gelar yaitu Mupakat Kamar, Mupakat Pandia Paku Sakha, dan Mupakat Balak. Masing-masing tahapan menjadi acuan bagi Jakhu Suku dalam melaksanakan prosesi ritual pemberian gelar. Berdasarkan temuan lapangan bahwa tahapan kerja Jakhu Suku dapat dibagi dalam tahapan pekhsiapan (persiapan), khencana (perencanaan), lestakhi (pelaksanaan), penghengok (dukungan) dan penghanggum (kepercayaan). Terdapat lima tahapan yang dilakukan secara berulang dan khas pada setiap ritual pemberian gelar atau Juluk Adok. Temuan lapangan tersebut membangun pola perilaku komunikasi Jakhu Suku dalam mengelola relasi budaya. Pola yang dimaksud adalah Pola Mupakat Kamar, Mupakat Pandia Paku Sakha, dan Pola Mupakat Balak.

Pekhsiapan diambil dari bahasa daerah Lampung yang merujuk pada persiapan. Simbolisasi Pekhsiapan mengandung makna bahwa langkah awal yang dilakukan oleh
Jakhu Suku yaitu mempersiapkan informasi dan data terkait dengan rencana pernikahan dari pasangan yang akan mendapatkan gelar. Informan Dalom Mangku Makhga menyebutkan bahwa langkah persiapan membantu Jakhu Suku dalam menentukan seting lokasi, waktu, sistem dan status pernikahan, serta perangkat adat yang diperbolehkan terlibat pada setiap tahapan ritual mupakat adat. Langkah pekhsiapan dibagi dalam dua tahapan yaitu tahapan Mupakat Kamar dan Mupakat Pandia Paku Sakha. Mupakat Kamar bertujuan menetapkan sistem dan status pernikahan. Mupakat Pandia Paku Sakha menetapkan jenis gelar yang akan diberikan pada calon penerima gelar. Mupakat Pandia Paku Sakha mengacu pada keputusan sistem dan status pernikahan. Pernikahan merupakan gerbang untuk mendapatkan gelar sehingga status atau kedudukan sangat berpengaruh terhadap jenis gelar. Jalur gelar mengikuti gelar orangtua yang berstatus mengambil anak menantu. Mupakat Kamar dilakukan Jakhu Suku bersama orangtua dari calon penerima gelar. Mupakat Pandia Paku Sakha melibatkan Jakhu Suku dan pimpinan adat.

Khencana adalah istilah yang juga diambil dari bahasa daerah Lampung yang artinya perencanaan. Upaya yang dilakukan Jakhu Suku yaitu membuat perencanaan yang mengacu pada hasil pekhsiapan (persiapan). Jakhu Suku menetapkan rangkaian dan jenis ritual, tema ritual, dan tujuan ritual. Khencana atau perencanaan dilakukan pada porsesi ritual Mupakat Balak. Mupakat yang bertujuan menetapkan konsep upacara pemberian gelar. Tema yang dibicarakan mengenai kesesuaian antara gelar yang diperoleh dengan rangkaian ritual yang akan dilaksanakan dan atribut adat yang dikenakan. Rangkaian ritual yang ditetapkan meliputi Dekorasi, Manjau Maju, Akad Nikah, Deduaian, Ngarak, Buka Pintu, Ngahantok, Nyebakh Adok, Doa dan Pangan. Sedangkan atribut yang digunakan pada rangkaian dekorasi berupa Khekhedaian, Kebung, Tikhai, Kasokh Kelulung, Tudung Gobekh dan Payan. (Hidayat, 2016:85). Setiap kelompok gelar diberlakukan rangkaian ritual 
berbeda. Demikian pula dengan jenis atribut, warna, dan jumlah atribut. Perlakukan berbeda mengacu pada kelompok gelar. Masyarakat adat Saibatin mengenal tiga kelompok gelar meliputi kelompok gelar pimpinan adat, Jakhu Suku, dan Khekhayahan.

Pelaksanaan termasuk bagian selanjutnya dari tahapan kerja Jakhu Suku. Pelaksanaan yaitu mengimplementasikan semua rangkaian kegiatan yang telah ditetapkan pada Mupakat Balak. Informan Wirakrama menyebutkan bahwa pelaksanaan pemberian gelar diawali dengan membuat dekorasi atau memasang atribut, membuat tempat memasak atau Nyanik Tungku, membuat penganan adat Lepot Tapai, dan pelaksanaan ritual-ritual sebelum gelar disampaikan atau Nyebakh Adok. sekaligus penghanggum atau kepercayaan. Penghengok dan Penghanggum diakui Wirakrama sebagai bentuk totalitas, loyalitas dan komitmen masyarakat di lingkungan adat maupun masyarakat luar. Penghengok dan penghanggum sebuah simbolisasi kasih sayang yang diberikan atas keyakinan, kecintaan dan kepatuhan terhadap tradisi adat yang sifatnya organik atau diwariskan. Tahapan kerja Jakhu Suku meliputi Pekhsiapan-KhencanaPelaksanaan-Penghengok dan Penghanggum terjadi secara khas dan berulang pada setiap ritual pemberian gelar. Peristiwa ritual tersebut membangun perilaku komunikasi Jakhu Suku sebagai PR Budaya. Perilaku komunikasi Jakhu Suku pada mupakat adat meliputi Mupakat Kamar, Mupakat Pandia Paku Sakha dan

Gambar 2.

The IPPAR Model; Komponen Perilaku Komunikasi Jakhu Suku Sebagai PR Budaya
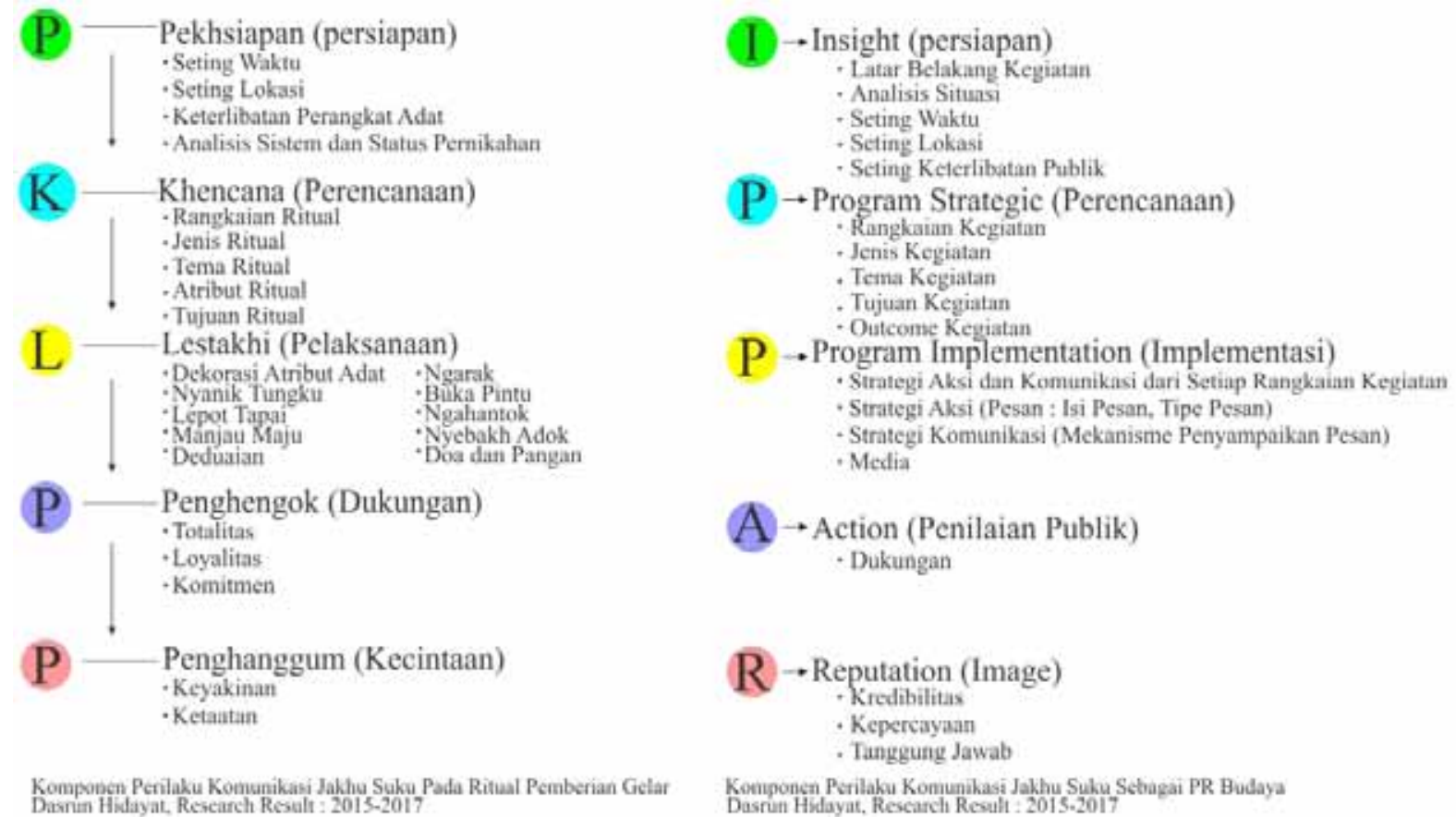

\section{Sumber: Dasrun Hidayat, Hasil Penelitian 2015-2017}

Temuan lapangan juga menekankan pada perilaku Jakhu Suku yang mengontrol atau melakukan evaluasi setiap rangkaian ritual. Menurut Wirakarama bahwa setiap ritual prosesi pemberian gelar diharapkan dapat menghasilkan dukungan dari masyarakat atau penghengok
Mupakat Balak.

The IPPAR Model dan Komponen Perilaku Komunikasi Jakhu Suku Sebagai PR Budaya

Komponen perilaku komunikasi Jakhu Suku mengacu pada originalitas temuan hasil 
penelitiantentang pola perilakukomunikasi Jakhu Suku dalam mengelola prosesi ritual pemberian gelar. Temuan pola perilaku komunikasi Jakhu Suku menjadi novelty atau originalitas hasil penelitian. Pola perilaku komunikasi meliputi aspek pekhsiapan (persiapan), khencana (perencanaan), lestakhi (pelaksanaan), penghengok (dukungan) dan penghanggum (kepercayaan). Konsep perilaku komunikasi Jakhu Saku memiliki kesamaan dengan prinsip dasar perilaku komunikasi Public Relations yakni selalu menggunakan pendekatan Management Public Relations (MPR). Cutlip menjelaskan bahwa MPR meliputi tahapan analisis situasi untuk mendefinisikan masalah, membuat strategi sebagai bagian dari perencanaan, melaksanakan strategi aksi dan komunikasi, serta melakukan evaluasi kegiatan (Cutlip, 2011:341). Kesamaan komponen perilaku antara Jakhu Suku dengan PR mendorong peneliti untuk mentransformasikan hasil temuan tentang pola perilaku komunikasi Jakhu Suku ke dalam lintas perspektif yakni ilmu Public Relations dan budaya.

Pola perilaku komunikasi Jakhu Suku pada ritual pemberian gelar dalam perspektif ilmu Public Relations dapat digambarkan melalui konsep-konsep yang berkaitan dengan perencanaan komunikasi PR. Smith memperkenalkan dengan istilah Insight atau menetapkan latar belakang kegiatan (Smith, 2005:17). Tench dan Yeomans menggunakan konsep Situation Analaysis atau analisis situasi. Analisis situasi bertujuan untuk memetakan seting tempat, waktu, dan keterlibatan publik. (Tench, Yeomans, 2006:193).Austin menjelaskan bahwa salah satu perencanana komunikasi PR adalah melakukan analisis publik. Analisis publik bertujuan untuk menetapkan fokus sasaran (Austin, 2008:27). Perencanaan komunikasi merupakan bagian dari perilaku komunikasi PR untuk membantu dan mempermudah pencapaian tujuan aktivitas PR (Tench, Yeomans, 2006:185).

Konsep perencanaan komunikasi PR juga berkaitan dengan penetapan Program Strategic. Cutlip menekankan bahwa program strategi sebagai langkah perencanaan pembuatan dan menetapkan jenis kegiatan, tema, tujuan dan outcomes (Cutlip, 2011: 341). Cutlip juga menambahkan tahapan Program Implementation atau implementasi dari setiap kegiatan. Implemenatasimemperhatikan faktorstrategiaksi meliputi pesan dan isi pesan. Strategi komunikasi berkaitan dengan mekanisme penyampaian pesan termasuk keputusan dalam memilih media. Semua tahapan perencanaan komunikasi PR dilakukan untuk mendapatkan dukungan dan kepercayaan publik. Dukungan tersebut berupa hasil penilaian atau Action and Reputasi. Reputasi atau jejak rekam. Minimal ada tiga aspek yang diperhitungkan dalam menanamkan reputasi. Aspek dalam membangun reputasi terdiri dari adanya tanggung jawab, kepercayaan dan keandalan (Ardianto, 2012:25). Konsepkonsep tersebut peneliti kategorikan sebagai komponen perilaku komunikasi Jakhu Suku sebagai PR Budaya. Komponen yang digunakan dalam membuat perencanaan komunikasi PR. Tench menegaskan bahwa perilaku komunikasi PR dengan membuat perencanaan komunikasi untuk membantu efektivitas kerja PR (Tench, 2004:185).

Berdasarkan kajian teoritis dan temuan originalitas lapangan peneliti merangkum komponen perilaku komunikasi Jakhu Suku sebagai PR Budaya ke-dalam beberapa aspek meliputi Insight - Program Strategic - Program Implementation - Action and Reputation atau The IPPAR Model. Konsep ini menjadi kerangka kerja atau Jakhu Suku framework pada ritual pemberian gelar. Ritual yang senantiasa mengacu pada tahapan analisis situasi, perencanaan, implementasi dan evaluasi. The IPPAR Model mencoba menjelaskan tahapan kerja Jakhu Suku dalam merancang kegiatan ritual pemberian gelar. Diharapkan model ini dapat digunakan pula pada cara kerja PR dalam konteks berbeda. Kesamaan komponen perilaku komunikasi antara Jakhu Suku dengan PR memperkuat bahwa The IPPAR Model dapat digunakan sebagai perencanaan kerja dalam membuat Blue Print PR.

Proses transformasi temuan hasil penelitian tentang komponen perilaku 
komunikasi Jakhu Suku pada ritual pemberian gelar dirumuskan ke dalam The IPPAR Model. Komponen perilaku yang terdiri dari aspek Insight adalah awal aktivitas Jakhu Suku untuk menentukan latar belakang kegiatan. Tench menyebut insight dengan istilah Situation Analaysis atau melakukan analisis situasi (Tench, 2006:188). Hasil dari tahapan insight yakni memetakan seting lokasi, dan waktu pelaksanaan kegiatan. Pada tahapan ini Jakhu Suku juga menetapkan Public atau partisipant yang akan dilibatkan pada setiap ritual pemberian gelar. Terdapat keterlibatan publik berbeda-beda disetiap ritual. Selektivitas dalam menetapkan publik disebut Identifying Public. Tench menjelaskan bahwa Public Relations sejak awal kegiatan telah melakukan pemilahan partisipan yang akan dilibatkan. Hal ini dimaksudkan agar tujuan kegiatan tepat sasaran (Tench, 2006:192). Pentingnya mengetahui keterlibatan publik juga dipertegas Smith, bahwa salah satu tugas Public Relations dalam membuat perencanaan komunikasi adalah melakukan analisis publik. Analisis yang bertujuan untuk mengetahui sasaran kegiatan sehingga sasaran selaras dengan target program. Membuat inventarisasi publik merupakan langkah awal yang sejalan dengan analisis situasi dalam menentukan latar belakang kegiatan. (Smith, 2005:42).

Hal senada diungkapan Lee bahwa keterlibatan publik berpengaruh terhadap objek aktivitas Public Relations (Lee, 2012:13). Keterlibatan publik pada setiap prosesi ritual pemberian gelar mengalami perubahan. Hal ini menyusul adanya perubahan terhadap sistem dan status pernikahan. Perubahan perilaku masyarakat adat Saibatin terjadi seiring dengan adanya faktor pendidikan, pekerjaan, tempat tinggal, dan kehadiran teknologimedia. Misalnya, perubahan pada seting lokasi pelaksanaan ritual pemberian gelar, dan perubahan partisipan di setiap ritual mupakat adat. Perubahan perilaku juga diperkuat oleh Suranto. Setiap kelompok sosial akan mengalami dinamika. Perubahan terjadi karena kelompok sosial bersifat dinamis dan adanya tujuan yang akan dicapai. (Suranto:
2010:109).

Komponen perilaku komunikasi Jakhu Suku berdasarkan The IPPAR Model selanjutnya adalah membuat perencanaan berupa Program Strategic. Tahapan ini menekankan pada jenis ritual, tema ritual, tujuan dan outcomes ritual. Tench menegaskan bahwa Program Strategic sebagai upaya menempatkan perencanaan yang sesuai dengan tujuan akhir kegiatan (Tench, 2006:196). Hal ini pula yang menjadi perhatian Jakhu Suku dalam mengelola ritual pemberian gelar. Ia senantiasa menyesuaikan keputusan awal tentang sistem dan status pernikahan. Hal ini dilakukan karena sistem dan status pernikahan berpengaruh terhadap rangkaian ritual, tema, dan tujuan ritual pemberian gelar.

\section{Menetapkan Program Implementation}

yakni komponen perilaku komunikasi Jakhu Suku dengan melaksanakan semua rangkaian ritual yang telah ditetapkan. Pelaksanaan ritual memperhatikan strategi aksi dan komunikasi. Jakhu Suku mengatur mekanisme pesan dan cara menyampaikan pesan pada prosesi ritual pemberian gelar. Tahapan ini menekankan pada mekanisme atau urutan dalam pelaksanaan kegiatan. Temuan hasil penelitian dipertegas Austin. Ia meyebutkan bahwa strategi aksi dan komunikasi bertujuan untuk mengatur mekanisme pelaksanaan kegiatan. Mekanisme pemilihan pesan, dan cara menyampaikan pesan sehingga mudah dan dapat diterima publik (Austin, Pinkleton, 2006:46).

Semua perencanaan pada program strategic diharapkan dapat berjalan sesuai dengan tujuan. Perencanaan sangat membantu Jakhu Suku dalam membangun dukungan dan kepercayaan publik. Kepercayaan tersebut penting sebagai bentuk penilaian publik terhadap reputasi atau Action and Reputation. Bagian terakhir dari kegiatan ini Tench menyebutnya dengan istilah evaluation and review (Tench, 2006:202). Mengkaji kembali atas keberhasilan dan kendala yang terjadi selama pelaksanaan kegiatan. Kegiatan review berdasarkan penilaian publik terhadap pelaksanaan atas perencanaan komunikasi Public Relations. 
Temuan perilaku komunikasi Jakhu Suku sebagai PR Budaya berupa perilaku verbal dan nonverbal. Perilaku verbal ditemukan disetiap Mupakat Adat selalu diawali dengan ucapan Tabik Puuun... dan akan dijawab Iya Puuunn.. Kalimat sebagai simbolisasi permintaan atau meminta izin untuk berbicara. Selain perilaku verbal juga perilaku sebagai simbol fisik. Simbol ini ditemukan di setiap atribut adat yang digunakan pada prosesi ritual pemberian gelar. Demikian pula perilaku nonverbal terdapat pada gerakan seperti menempelkan kedua tangan di depan dada ketika akan meminta izin berbicara. atau PR Budaya. Kajian tersebut memerlukan metodologi khusus dan khas yaitu Etnografi PR. Landasan dasar metodologi Etnografi PR adalah perilaku komunikasi PR berbasis budaya. Secara eksplisit tokoh-tokoh PR menjelaskan beberapa prinsip dasar tentang keterkaitan antara perilaku komunikasi PR dengan unsur komunikasi dan budaya. Komunikasi adalah tulang punggung Public Relations atau communication is backbone of public relations. (Alison, Theaker: 2004:25). Aktivitas PR tidak dapat dilakukan tanpa adanya komunikasi, sehingga komunikasi merupakan salah satu komponen dari strategi

\section{Gambar 3.}

\section{Simbolisasi Perilaku Jakhu Suku Pada Ritual Mupakat Pandia Paku Sakha}

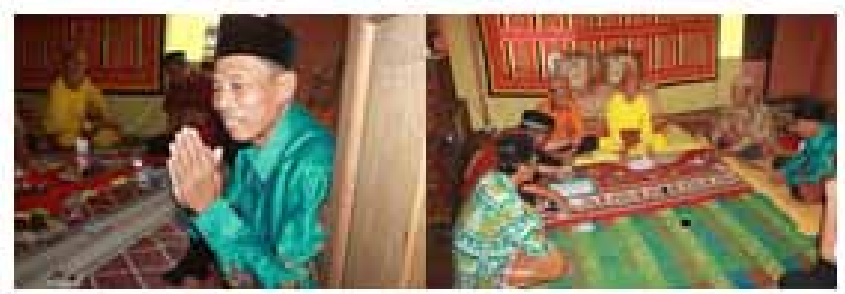

\section{Sumber: Dokumentasi Pribadi: 2016}

Temuan komponen perilaku komunikasi Jakhu Suku pada ritual pemberian gelar merupakan tindakan dalam berkomunikasi. Menurut Mulyana tindakan meliputi tindakan verbal dan nonverbal (Khairil, 2012:121). Tindakan Jakhu Suku menekankan pada mekanisme yang telah disepakati secara adat. Perilaku yang dipraktikkan menjadi bagian dari upaya membangun relasi budaya atau membangun pemahaman masyarakat tentang nilai-nilai kearifan budaya sehingga dapat menciptakan dukungan dan kepercayaan publik secara utuh.

\section{Transformasi Etnografi PR}

Temuan perilaku komunikasi Jakhu Suku pada ritual pemberian gelar meliputi aspek pekhsiapan (persiapan) khencana (perencanaan) lestakhi (pelaksanaan) penghengok (dukungan) dan penghanggum (kepercayaan) atau PKLPP. Aspek-aspek yang kedudukannya sebagai temuan originalitas penelitian atau kebaruan (novelty). Temuan tersebut ditranformasikan ke dalam kajian Public Relations berbasis budaya kerja PR.

Sriramesh menjelaskan bahwa fokus utama ilmu Public Relations adalah perilaku komunikasi untuk membangun hubungan (Sriramesh, 2004:03). Sriramesh juga menyebutkan bahwa budaya merupakan mata rantai yang hilang dari ilmu Public Relations atau Culture and Public Relations: The Missing Link. Di era globalisasi ini mata rantai tersebut harus dikembalikan dengan menempatkan budaya di garda terdepan pada penelitian organisasi, komunikasi, dan Public Relations. Mata rantai yang hilang juga membuka peluang penelitian di bidang ilmu Public Relations yang dapat melahirkan konsep, teori, dan metodologi Public Relations.

Diperlukan perencanaan komunikasi bagi seorang PR. Perencanaan sebagai bagian dari perilaku komunikasi PR bertujuan untuk membantu PR dalam memetakan fokus masalah, meramalkan perilaku, dan membuat aktivitas $P R$ berjalan efektif (Tench, 2004:185). Perencanaan 
diawali dengan analisis situasi untuk membuat identifikasi, inventarisasi, dan pemetaan terhadap aktivitas publik. Aktivitas ini didorong oleh perilaku yang dipengaruhi nilai-nilai yang dibangun dalam sistem perusahaan atau lembaga. (Baines, Eagan, Jefkins, 2004:96).

Perilaku Komunikasi PR selalu mengacu pada prinsip perencanaan. Konsep dasar yang relevan dengan prinsip PR yakni manajemen POAC meliputi Planning-Organizing-ActuatingControling. (Dubrin, 2008:210). Hal senada dipertegas oleh Cutlip dalam konsep Management of Public Relations (MPR). Aktivitas PR diawali dengan analisis situasi, membuat perencanaan, strategi kegiatan, implementasi kegiatan, dan evaluasi kegiatan (Cutlip, 2011:341).

Perilaku publik disetiap kelompok masyarakat, komunitas, perusahaan selalu melibatkan nilai-nilai yang disepakati. Nilai tersebut berupa budaya institusi atau budaya organisasi. Seville-Troike menyebutkan bahwa etnografi fokus pada budaya pada kelompok masyarakat tertentu (Kuswarno, 2008:35). Pada Etnografi PR adalah budaya publik dan stakeholder di dalam kelompok masyarakat, organisasi atau lembaga PR lainnya.

\section{PR Budaya dan Etnografi PR}

Hubungan konseptual antara Public Relations dengan budaya menunjukkan bahwa adanya peluang penelitian untuk mengembangkan konsep ilmu PR (Sriramesh, 2004:3). Berdasarkan pemikiran tentang pertemuan antara konsep budaya dengan PR maka peneliti menawarkan istilah PR Budaya. Istilah tersebut juga diperkuat oleh hasil penelitian yang menemukan adanya keterlibatan antara prinsip dasar perilaku komunikasi PR dengan perilaku komunikasi Jakhu Suku di dalam menjalankan ritual pemberian gelar. Keterlibatan terdapat pada cara kerja yang menempatkan proses perencanaan di setiap ritual pemberian gelar. Kesamaan lainnya pada tujuan perencanaan ritual yakni untuk memperkenalkan atau melakukan branding terhadap adat istiadat berupa tradisi pemberian gelar atau Juluk Adok.

Konsep PR Budaya juga dilatar belakangi oleh berbagai situasi berbeda antara Indonesia dengan negara-negara Barat dan Eropa. Indonesia kaya akan budaya dan nilai kearifan lokal sehingga kajian Public Relations berbasis budaya sangat dibutuhkan. Konsep tentang budaya dan Public Relations hadir sejak tahun 1990-an. Pakar Public Relations sudah memprediksi keterlibatan budaya dalam perilaku komunikasi PR di era globalisasi. Srirames memaparkan realita adanya mata rantai yang hilang antara budaya dan Public Relations atau culture and Public Relations: The Missing Link. Mata rantai tersebut seharusnya hadir sehingga dapat memperkuat perencaaan komunikasi PR. Siramesh menyadari pentingnya unsur budaya sebagai strategi perencanaan komunikasi PR di tengah aktivitas PR modern. (Sriramesh, 2004:3). Hal ini dipertegas Tench dan Yeomans bahwa fokus kajian ilmu PR adalah perilaku komunikasi sehingga Public Relations harus memahami tentang perencanaan komunikasi (Tench dan Yeomans, 2004:185). Hal senada juga diungkapkan Sriramesh bahwa ilmu PR mempelajari perilaku komunikasi untuk membangun hubungan (Sriramesh, 2004:3).

Perilaku komunikasi PR bertujuan untuk membangun hubungan (Sriramesh, 2004:3). Upaya membangun hubungan dipengaruhi oleh aspek budaya. Lembaga atau organisasi adalah miniatur terkecil budaya sehingga setiap lembaga tidak lepas dari budaya. Asumsi tersebut yang menjadi kerangka lahirnya pemikiran tentang konsep PR Budaya. Hal ini juga diperkuat Ming Yi bahwa perencanaan komunikasi PR di abad 21 memiliki karakteristik selalu berpikir global dan bertindak lokal. Menurut Ming-Yi bahwa cara kerja PR paling efektif adalah memahami budaya lokal, namun tetap memiliki strategi berpikir global (Ming-Yi, 2009). Srirmesh menegaskan bahwa di abad 21 menempatkan budaya di garis terdepan pada penelitian organisasi dan perencanaan komunikasi Public Relations (Sriramesh, 2010:73). Hal serupa juga diungkapan hasil penelitian Albu bahwa memahami cara kerja PR international harus diawali dengan upaya memahami budaya 
setempat (Albu: 2013).

Perencanaan komunikasi PR berkaitan dengan langkah-langkah yang akan dilakukan PR dalam mengatasi berbagai isu PR. Isu berdasarkan perspektif PR Budaya meliputi komunitas, etika dan profesionalisme, komunikasi internal, konsumen, marketing komunikasi, citra lembaga, reputasi, dan identitas lembaga. Isu tentang politik, demokrasi, feminisme hingga isu hiburan dan seni. Isu aktivitas PR Budaya tidak terbatas pada konteks lembaga PR profit, akan tetapi juga pada PR non-profit. Aktivitas PR juga tidak lepas dari keberadaan media PR. Media terdiri dari media internal dan eksternal. Isu tentang aktivitas PR juga terintegrasi dengan perkembangan media digital atau media berbasis teknologi seperti media baru dan sosial media. secara keilmuan Public Relations merupakan bagian di dalam ilmu komunikasi. Sedangkan dari perspektif perilaku komunikasi PR maka komunikasi sebagai alat dan strategi kerja PR. Kedudukan komunikasi dan PR sangat menentukan perencanaan komunikasi PR.

Roadmap PR Budaya yang terdapat pada gambar 3 memberikan ilustrasi tentang pemetaan PR Budaya sebagai bidang ilmu Public Relations. PR Budaya senantiasa menempatkan aspek komunikasi dan budaya sebagai strategi komunikasi PR. Tahapan yang dapat dilakukan olehPRadalah membuat perencanaankomunikasi meliputi analisis situasi, memetakan seting lokasi, waktu, dan publik yang terlibat dalam kegiatan. Aktivitas PR juga harus memperhatikan program strategi sebagai bagian dari perencanaan

Gambar 4.

\section{Roadmap Culture Public Relations Based on Local Wisdom}

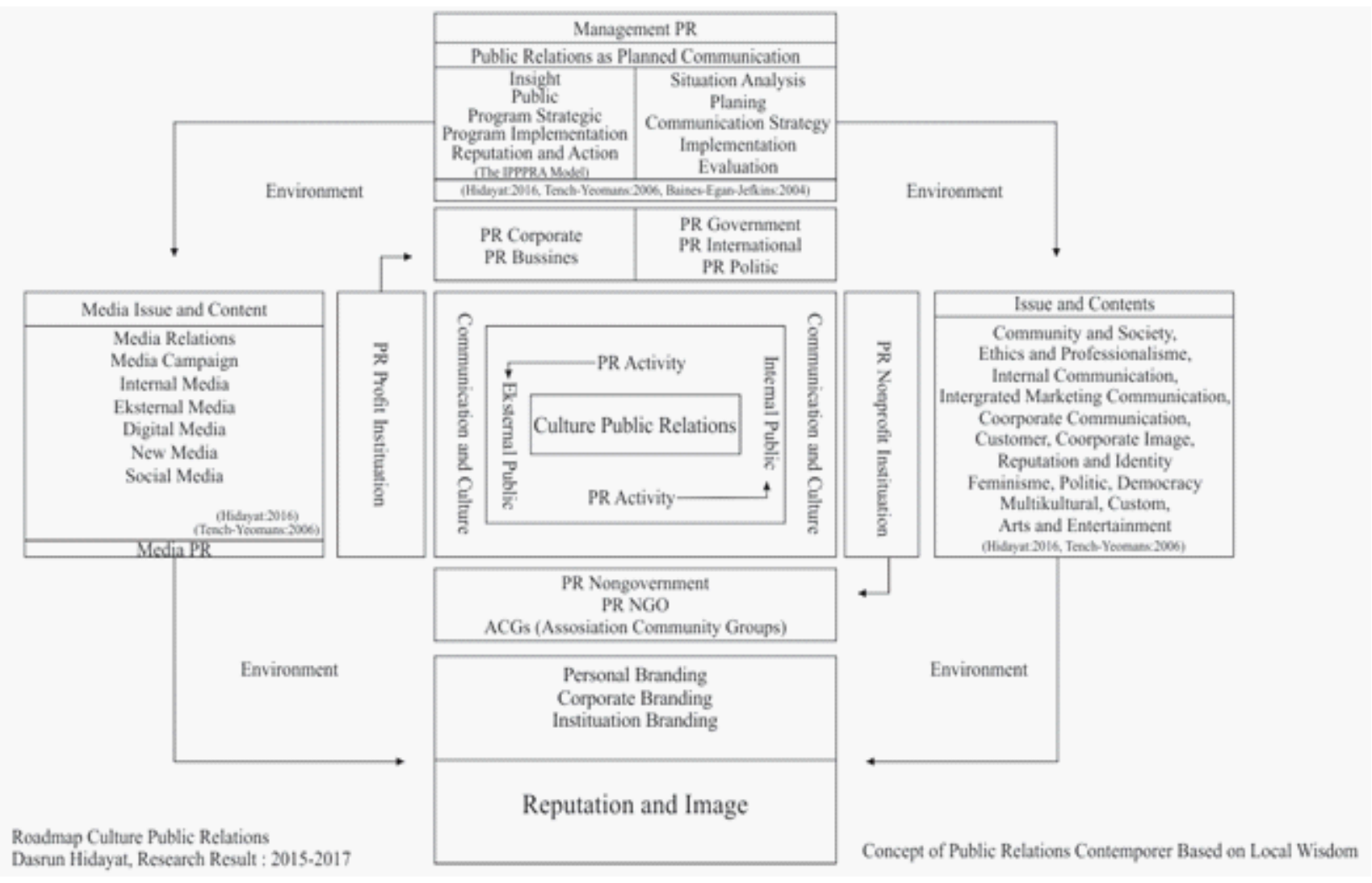

Komunikasi merupakan aspek penting dalam perilaku komunikasi PR. Komunikasi adalah tulang punggung PR. Komunikasi sebagai alat kerja PR. Ditinjau dari kedudukan komunikasi. Strategi meliputi menetapkan jenis kegiatan, tema, tujuan, dan outcomes kegiatan. Semua perencanan tersebut diimplementasikan sesuai dengan tujuan perencanaan kegiatan. 
Implementasi kegiatan berkaitan dengan strategi aksi dan komunikasi meliputi pesan, mekanisme atau cara menyampaikan pesan. Implementasi perencanaan komunikasi diharapkan dapat membantu menarik dukungan, dan kepercayaan publik sehingga PR mampu menciptakan, dan mempertahankan reputasi lembaga.

PR Budaya atau perilaku komunikasi PR berbasis budaya memerlukan metodologi khusus dan khas. Metodologi yang dapat menjelaskan komponen perilaku komunikasi PR sehingga dapat membangun pola kerja PR. Metodologi yang ditawarkan adalah Etnografi. Etnografi sebagai metodologi sifatnya cair sehingga melahirkan etnografi-etnografi lainnya seperti Etnografi PR. Metodologi Etnografi PR berkaitan dengan Etnografi Komunikasi karena fokus yang dikaji adalah perilaku komunikasi (Kuswarno, 2008:35).

Fokus kajian Etnografi PR adalah perilaku komunikasi PR. Perilaku yang didasarkan pada fungsi manajemen (Cutlip, 2011:57). Sedangkan komunikasi merupakan fokus kajian ilmu PR (Sriramesh, 2004:3). Perilaku komunikasi PR sebagai fokus Etnografi PR dengan pendekatan Manajemen PR bertujuan untuk menganalisis situasi, mengidentifikasi, memetakan, menginventarisasi perilaku komunikasi individu-individu dalam tema kebudayaan tertentu. Perilaku komunikasi dalam tema kebudayaan tertentu dipertegas pula dalam Etnografi Komunikasi (Kuswarno, 2008: 35). Komponen perilaku komunikasi PR terdiri dari Insight-Program Strategic-Program Implementation-Action and Reputasi atau The IPPAR Model. (Hidayat, 2016:84).

\section{Teknik Pengumpulan Data Etnografi PR}

Teknik pengumpulan data Etnografi PR tidak terlalu jauh berbeda dengan Etnografi Komunikasi. Keduanya memiliki kesamaan karena fokus kajian adalah perilaku komunikasi. Etnografi komunikasi menekankan pada langkah intropeksi, tindakan ini dilakukan ketika peneliti meneliti kebudayaannya sendiri sehingga diperlukan upaya mengoreksi diri sendiri atau mencoba melepaskan diri dari objek yang sedang diteliti. Selanjutnya melakukan observasi, wawancara, analisis dokumen. (Kuswarno, 2008:48). Demikan halnya dengan teknik pengumpulan data pada Etnografi PR. Pengumpulan data menekankan pada teknik yang biasanya digunakan pada Etnografi Komunikasi.

Observasi Partisipan atau melakukan pencarian data secara langsung atau on the spot data. Berpartisipasi artinya etnografer berada di dalam masalah penelitian dengan melibatkan diri pada aktivitas publik atau informan penelitian. Data etnografi bersifat alami sehingga peneliti sebagai etnografer dituntut untuk pandai dalam memainkan peran di lapangan sebagai partisipan. Observasi Tanpa Partisipan. Tahapan mencari data tanpa adanya keterlibatan etnografer di dalam kelompok masyarakat yang sedang diteliti. Aktivitas publik hanya diamati tanpa adanya partisipasi sebagai bagian dari aktivitas etnografer.

Wawancara Mendalam merupakan metode riset dengan menggunakan wawancara tatap muka (Sobur, 2014:854). Wawancara mendalam akan menghasilkan data secara terperinci dan sistematis. Etnografer pada penelitian Etnografi PR seyogyanya memahami konsep dan objek kajian penelitian Etnografi PR. Hal ini dapat mempermudah etnografer dalam memetakan pertanyaan wawancara. Kajian Dokumentasi. Teknik pencarian data yang bersifat data sekunder melalui berbagai telaah dokumentasi dan referensi relevan meliputi tulisan, artifak, foto dan lainnya. Kajian dokumentasi ini penting sebagai dasar pemahaman maupun untuk memperkuat hasil penelitian di lapangan.

Focus Group Discussion. Teknik pengumpulan data yang memiliki ciri tertentu yakni mengundang dan melibatkan para informan dan partisipan dalam diskusi kelompok. Diskusi yang dimaksud adalah diskusi terarah artinya memiliki tema dan topik pembicaraan sebagai bahan diskusi. Informan yang terlibat beragam, dan disesuaikan dengan kebutuhan penelitian. Pada tahapan teknik Focus Group Discussion, tantangan bagi etnografer terhadap kemampuan 
dirinya dalam menguasai masalah yang diteliti. Ia sebagai pemandu diskusi sekaligus yang mengarahkan pembicaraan yang tidak keluar dari tema diskusi.

\section{Otentitas Data Etnografi PR}

Prinsip otentitas data Etnografi PR sama dengan Etnografi Komunikasi. Otentitas atau teknik keabsahan data Etnografi PR mengacu pada teknik yang dikemukan oleh Moleong dalam Kuswarno. Teknik tersebut meliputi perpanjangan keikutsertaan, ketekunan, triangulasi, analisis kasus negatif, dan menyediakan referensi relevan (Kuswarno, 2008:66).

Teknik keabsahan data bertujuan untuk mendapatkan otentitas data. Langkah etnografer meliputi (a) perpanjangan keikutsertaan etnografer dalam aktivitas kelompok masyarakat yang diteliti dalam waktu yang lama. (b) Ketekunan pengamatan, yaitu upaya yang cermat untuk menemukan ciri-ciri, dan unsurunsur dalam situasi yang relevan dengan masalah penelitian. (c) Triangulasi. Kroscek data dengan memperhatikan tiga unsur yaitu metode, waktu dan sumber data. (d) Analisis kasus negatif, mengumpulkan contoh kasus atau temuan yang tidak sesuai dengan kecendrungan dan pola informasi yang telah dikumpulkan dan digunakan sebagai bahan pembanding. (e) Kecukupan referensi, mengumpulkan data tertulis secara lengkap sehingga membantu dalam interpretasi data hasil lapangan. (f) Review, artinya melakukan audit data melalui pemeriksaan terhadap seluruh data mulai dari data mentah pada data hasil reduksi, deskripsi, dan analisis.

\section{Analisis Data Etnografi PR}

Persamaan secara aplikatif lainnya terdapat pada teknik analisis data. Metode Etnografi PR menggunakan teknik analisis data yang umum digunakan pada metode Etnografi Komunikasi. Teknik analisis data meliputi reduksi, deskripsi dan analisis atau interpretasi data.

Tahapan reduksi adalah tahapan etnografer mengolah data dengan membuat transkrip hasil wawancara maupun transkrip atas catatan hasil observasi. Deskripsi tersebut juga dapat berupa display kategorisasi data atau matriks data. Display data bertujuan untuk memetakan data berdasarkan sub-sub tema temuan penelitian yang akan menjawab masingmasing dari pertanyaan penelitian. Tahapan selanjutnya etnografer menuliskan beberapa data penting atau melakukan high light data yang dapat menjawab tujuan penelitian. Data akurat yang diambil dari data display berupa tabel, grafik, diagram, model yang dapat menggambarkan objek penelitian. Tahapan reduksi merupakan implementasi pengolahan konstrak drajat ke satu. Pada tahapan ini etnografer memetakan aspek-aspek penting yang berhubungan dengan sub tema temuan penelitian.

Data high light selanjutnya dideskripsikan pada sub-bab hasil penelitian. Deskripi high light data dituangkan melalui tiga point utama. Point pertama pemaparan prolog yang berkaitan dengan data yang akan disampaikan. Point kedua memaparkan data lapangan berupa kutipan langsung pernyataan informan yang sudah direduksi atau high light. Point ketiga memberikan deskripsi atas high lihgt data atau kutipan pernyataan informan. Proses deskripsi high light data disebut pula sebagai langkah konstruk drajat ke-dua.

Tahapan analisis data berikutnya adalah melakukan konstruk drajat ke-tiga. Langkah yang dilakukan oleh etnografer yaitu menginterpretasi data. Pada tahapan ini etnografer melakukan analisis, teoritisasi data atau mengkonfirmasi data berdasarkan teori yang relevan. Interpretasi dapat dilakukan melalui triangulasi data berdasarkan teori, untuk memperkuat menerima atau menolak hasil penelitian. Triangulasi juga dapat berupa konfirmasi data berdasarkan sumber informan, waktu, dan teknik pengumpulan data. Simpulan

Etnografi sebagai metodologi sifatnya cair artinya bahwa etnografi akan selalu berkembang sesuai dengan kebutuhan penelitian. Etnografi PR merupakan tranformasi etnografi komunikasi. Etnografi PR sebagai metodologi 
mangacu pada temuan komponen perilaku komunikasi Jakhu Suku sebagai PR Budaya pada prosesi ritual pemberian gelar. Ritual yang dilakukan oleh Jakhu Suku sebagai PR Budaya menekankan pada aspek perilaku komunikasi Jakhu Suku berupa pekhsiapan (persiapan), khencana (perencanaan), lestakhi (pelaksanaan), penghengok (dukungan) dan penghanggum (kepercayaan). Aspek perilaku komunikasi Jakhu Suku sebagai temuan sekaligus originalitas hasil penelitian. Originalitas temuan selanjutnya ditranformasi melalui perspektif ilmu Public Relations dan Budaya. Transformasi menghasilkan komponen perilaku komunikasi Jakhu Suku sebagai PR Budaya meliputi Insight -Program Strategic - Program Implementation Action and Reputasi. Komponen yang mengacu pada konsep Manajemen PR terdiri dari Analisis situasi, Perencanaan, Implementasi dan Evaluasi.

Etnografi PR merupakan temuan sekaligus tawaran sebagai metodologi pada kajian PR berbasis budaya atau PR Budaya. Diharapkan temuan ini dapat berkontribusi terhadap pengembangan penelitian ilmu Public Relations. Penelitian PR yang tidak hanya dibatasi pada lembaga PR perusahaan, akan tetapi lembaga PR pemerintah dan nonpemerintah. Penelitian PR yang mencakup semua isu terkait dengan keberadaan kelompok masyarakat, organisasi dan institusi. Etnografi PR sebagai metodologi yang berfokus pada perilaku komunikasi PR dengan pendekatan kearifan budaya.

\section{Daftar Pustaka}

Albu, Ioana. (2013). Language, Meaning, Culture In International Public Relations. Proceeding Annual International Interdisciplinary Conference (AIIC) Portugal. 24-25. Ardianto, Elvinaro. (2013). Handbook of Public Relations. Bandung: Rosdakarya.

Austin, Pinkleton. (2008). Strategic Public Relations Management. Planning and Managing Effective Communication Programs. Second Edition. New Jersey: Lawrence Erlbaum Associates.
Baines, Egan, Jefkins. (2004). Public Relations Contemporary Issues and Techniques. England: Elsevier Butterworth Heinemann. Cutlip, Scoot. Broom. (2001). Effective Public Relations. $8^{\text {th }}$ Edition. USA: Prentice-Hall Inc.

Dubrin, Andrew J. (2008). Essential of Management.Canada:CengageLearning. Edwards, Lee. (2012). Defning the Object of Public Relations Research: A New Starting Point. Public Relations Inquiry. Jilid 1 (1). Hlm. 7-30. Hidayat, Dasrun. (2016). Etnografi Public Relations Tantangan Metodologi Pada Kajian Public Relations Berbasis Budaya. Prosiding Seminar Nasional Akselerasi Pembangunan Masyarakat Lokal Melalui Komunikasi dan Teknologi Informasi. Seminar Nasional. Universitas Lampung. ISBN: 978602-60412-0-3. Buku 2. Hlm 76-87 (2014). Representasi NemuiNyimah sebagai Nilai-Nilai Kearifan Lokal Lampung; Perspektif Public Relations Multikultur. Jurnal Ilmu KomunikasiUniversitas Riau. ISSN2252665X. Volume 5 Nomor 1. hlm 90-102. Hymes, Dell. (1996). Ethnography, Linguistics, Narative Inequality. London: Taylor and Francis.

Khairil, Muhammad. (2012). Perilaku Komunikasi Terpidana Kelompok Teroris. Jurnal Ilmu Komunikasi, Volume, Nomor, Agustus 2012. Jurusan Ilmu Komunikasi FISIP UPN Jogjakrta. Kuswarno,Engkus.(2008).EtnografiKomunikasi. Bandung: Widya Padjadjaran. Lim, Young, Goh, Sriramesh. (2005). Applicability of the Generic Principles of Excellent Public Relations in a Different Cultural Contex; The Case Study of Singapore. Journal Of Public Relations Research. Lawrence Erlbaum Associates, Inc 17(4) 315-340. 
Leicthy, Greg. (2003). The Cultural Tribes of Public Relations. Journal of Public Relations Research. Lawrence Erlbaum Associates, Inc volume 15:4hlm 277-304. Ling Sha, Bey. (2006). Cultural Identity in the Segmentation of Publics: An Emerging Theory of Intercultural Public Relations. Journal of Public Relations Research. Lawrence Erlbaum Associates, Inc volume 18:1 hlm 277-304. Ming Yi-Wu. (2009). Can American Public Relations Theories Apply to Asian Cultures? Journal Public Relations Quarterly (503) ProQuest Health Management.

Smith, Ronald. (2005). Strategic Planning for Public Relations. Second Edition. New Jersey: Lawrence Erlbaum Associates.

Sobur, Alex. (2015). Ensiklopedia Komunikasi. Bandung: Simbiosa Rekatama Media. Sriramesh, K., \& Vercic, D. (2009). The Handbook of Global Public Relations: Theory, Research, and Practice (Revised and Expanded Edition). New York: NY: Routledge.
(2006). International Public Relations; A Framework for Future Research. Journal of Communication Management. Volume 6. Nomor 2. Hlm. 103-117. ( $\left.\begin{array}{llll}2 & 0 & 0 & 4\end{array}\right)$. Multiculturalisme and Public Relations Education. The Global Public Relations Handbook Theory, Research and Practice. London: Lawrence Erlbaum Associates Publishers. (2004).

(Eds.) The Global Public Relations Handbook (Revised Edition). New York, NY: Routledge. 62 - 78 Suranto Aw. (2010). Komunikasi Sosial Budaya. Graha Ilmu: Jogjakarta

Tench, Yeomans. (2006). Exploring Public Relations. England: Person Education Theaker, Alison. (2004). The Public Relations Hand Book. London: Routledge 